\title{
KEBERADAAN DAN IMPLIKASI PRINSIP MFN DAN NT DALAM PENGATURAN HAK KEKAYAAN INTELEKTUAL DI INDONESIA ${ }^{1}$
}

Oleh :

Ni Ketut Supasti Dharmawan Wayan Wiryawan email : arasswk@yahoo.com email : wayan_wiryawan@yahoo.com ${ }^{2}$

\begin{abstract}
The WTO - TRIPs Agreement regulates the principle of non- discrimination which must be complied by its member countries. There are two principle of non discrimination namely the principle of National Treatment ( NT ) and Most Favoured Nations principle (MFN). This study focus to the adoption of MFN and NT principles into Intellectual Property Rights laws of Indonesia whether it harmony with the legal system in Indonesia.

This study uses the normative legal research methods by using conceptual approach and statute approach. The legal materials that studies in this research consists of the Primary Legal Materials : Act No. 19 of 2002 , Act No. No. . 15 of 2001, Act No. 14 of 2001, as well as the TRIPs Agreement. Secondary legal materials studied in this research are legal text books and law journals related to NT and MFN principle in the field of Intellectual Property Rights.

The results showed that the Principle of Non Discrimination System in the form of the principle of National Treatment (NT) expressly governed through Article 3 TRIPs Agreement and the principle of Most Favoured Nations (MFN) regulated through Article 4 TRIPS Agreement. As a member of WTO-TRIPs Agreement, Indonesia should comply and adopt the MFN and NT principles into IPR laws. Currently those principles exist implicitly and explicitly such as in the Act No. 19 of 2002, the Act No. 14 of 2001, and the Act No. 15 of 2001. Although the MFN and NT principles has already adopted, it is still need more effort to implement the principle of non Discrimination, especially in the relationship between Indonesia and other unequal size countries, between developing and developed countries.
\end{abstract}

Keywords : Intellectual Property Rights, MFN, NT, TRIPS Agreement.

${ }^{1}$ Karya ilmiah ini merupakan hasil penelitian yang dibiayai dari dana Dipa BLU Program Studi Magister (S2) Ilmu Hukum PPS UNUD dengan SK Direktur nomor: 1430/UN.14.4/HK/2013, telah di presentasikan dalam seminar/FGD di Program Magister (S2) Ilmu Hukum pada tanggal 11 Nopember 2013.

${ }^{2}$ Para penulis adalah Dosen pada Program Studi Magister (S2) Ilmu Hukum Program Pascasarjana Universitas Udayana (UNUD) dan Fakultas Hukum UNUD Denpasar-Bali 


\section{PENDAHULUAN}

\subsection{Latar Belakang Masalah}

Berawal dari empat pilar utama yaitu the rule against the use of quantities restrictions, the rule reduction tariffs and others barrier for trade, the rule of national treatment (NT) and the principle of most favored nation (MFN) yang digagas dalam GATT 1994 dan kemudian eksis dalam perjanjian perdagangan sedunia, yaitu the World Trade Organization (WTO) 1995, dinyatakan bahwa dengan 4 pilar utamanya organisasi internasional tersebut di atas telah mendukung libralisasi dan perdagangan bebas yang pada akhirnya semua negara anggotanya akan mendapat manfaat (benefit), termasuk kepulauan-kepulauan kecil di negara berkembang, yaitu the SIDS (Small Island Developing States). ${ }^{3}$ Dua dari 4 pilar tersebut di atas yaitu $M F N$ dan principle of $N T$ juga dikenal dengan sebutan Non Discrimination Pimples yaitu yang melarang adanya perlakuan diskriminasi di antara negara-negara anggota WTO. Perjanjian internasional di bidang perdagangan ini menekankan pentingnya non discrimination principle

3 Mooneeram \& Chadee Varsha, 2013, Understanding the Legal Framework of the Most Favoured Nation Rule from a SIDS perspective, ICITI, ISSN:16941225, University of Mauritius, Reduit Mauritius , p. 2-4. diterapkan oleh seluruh negara anggotanya, termasuk Indonesia yang juga negara anggota dari WTO.

Sebagai tindak lanjut dari keikutsertaan Indonesia sebagai anggota WTO, melalui U.U. No. 7 tahun 1994 Indonesia telah meratifikasi persetujuan WTO. Pada intinya negara anggota WTO wajib mentaati standar perdagangan internasional, namun demikian tetap memberikan pengecualian khususnya bagi negara berkembang dan negara yang paling terbelakang untuk mengatur secara khusus hal-hal yang dianggap penting dan sangat berkaitan dengan kebutuhan negaranya dalam koridor perkembangan perdagangan internasional. Sebagai negara anggota yang turut serta menandatangani persetujuan WTO, Indonesia wajib melaksanakan seluruh hasil kesepakatan WTO beserta Annexes atau lampirannya yaitu : TRIMs, TRIPs, dan GATS. Sebagaimana telah disebutkan sebelumnya bahwa pilar utama yang telah disepakati yaitu prinsip Non Discrimination yang meliputi Most Favoured Nation (MFN) dan National Treatment Principle (NT) tertuang dalam ke tiga Annexes of WTO Agreement yaitu dalam TRIMs, GATS dan TRIPs.

Prinsip NT dan MFN dalam Trade Related Intellectual Property Rights 
(TRIPs) diatur berdasarkan Article 3 dan Article 4. Prinsip NT pada intinya mensyaratkan adanya perlakuan yang sama antara produk negara tuan rumah dengan produk serupa dari luar negeri. Berdasarkan prinsip NT, tidak boleh ada keistimewaan perlakuan terhadap produk dalam negeri dan mendiskriminasikan produk sejenis dari negara anggota WTO lainnya. Sementara itu prinsip $M F N$ pada intinya menentukan bahwa perlindungan dan keistimewaan pada salah satu negara anggota, wajib diberikan secara sama, secepatnya dan tanpa syarat kepada negara anggota WTO lainnya. Prinsip yang melandasi persetujuan TRIPs yang mengatur perlindungan Hak Kekayaan Intelektual juga menegaskan bahwa bahwa siapapun (baik negara maju maupun negara berkembang) melakukan pelanggaran terhadap hukum HKI sebagaimana disepakati dalam TRIPs, pihak tersebut wajib mempertanggungjawabkannya.

Dengan mencermati kewajiban negara anggota melaksanakan prinsipprinsip WTO-TRIPs Agreement, yaitu wajib melaksanakan harmonisasi hukum di bidang HKI khususnya mengadopsi Prinsip $N T$ dan $M F N$, menjadi penting untuk dilakukan pengkajian, terutama untuk mengkaji secara lebih mendalam implikasi prinsip $N T$ dan $M F N$ dalam konstruksi pengaturan HKI di Indonesia pasca keikutsertaan Indonesia dalam WTOTRIPs Agreement, terutama untuk menganalisis apakah keberadaan prinsipprinsip tersebut yang berbasis liberal serta globalis tidak berbenturan atau harmoni dengan sistem hukum di Indonesia.

\subsection{Rumusan Masalah}

Karya tulis yang berbasis penelitian ini mengkaji dua permasalahan inti yaitu:

1. Bagaimana substansi prinsip-prinsip MFN dan NT dalam WTO-TRIPS Agreement?

2. Bagaimana keberadaan prinsip $M F N$ dan NT dalam pengaturan Hak Kekayaan Intelektual serta harmonisasinya dengan sistem hukum Indonesia?

\section{METODE PENELITIAN}

Metode yang digunakan dalam penelitian ini adalah metode penelitian hukum normatif. Penelitian dalam pelaksanaan dikerjakan secara metodologis, sistematis dan konsisten. ${ }^{4}$. Pendekatan yang dipergunakan adalah pendekatan perundang-undangan, perbandingan serta pendekatan konsep

4 Ciri-ciri penelitian sebagai bagian dari kegiatan ilmiah dikerjakan secara metodologis, sistematis dan konsisten. Lihat Jhony Ibrahim, 2006, Teori dan Metode Penelitian Hukum Normatif, Bayu Publishing, Malang, h. 26. dan h. 47. 
hukum. ${ }^{5}$ Bahan-bahan hukum yang diteliti meliputi bahan hukum primer yaitu WTO, TRIPs Agreement, U.U. No. 19 Tahun 2002, U.U. No. 14 Tahun 2001, U.U. No. 15 serta Tahun 2001. Sementara itu buku teks, literatur serta jurnal hukum yang berkaitan dengan HKI dikategorisasikan sebagai bahan hukum sekunder. Tehnik studi dokumen dipergunakan untuk mengambil dan mengidentifikasi Bahan Hukum, kemudian dianalisis dengan menggunakan analisis deskriptif kualitatif .

\section{III.HASIL DAN PEMBAHASAN}

\subsection{Substansi Prinsip NT dan $M F N$ Dalam TRIPs Agreement}

TRIPs Agreement mempersyaratkan standar minimum yang wajib dipenuhi oleh negara anggotanya dalam rangka perlindungan HKI. TRIPs merupakan suatu perjanjian yang komplek, komprehensif dan ekstensif. Menurut Christophe Bellmann, Graham Dutfield \& Melendez ${ }^{6}$ bahwa “... TRIPs, one of the main outcomes of the Uruguay Round of the

\footnotetext{
${ }^{5}$ Dalam penelitian hukum normatif dikenal berbagai jenis pendekatan yaitu : Case Approach, Statute approach, Historical approach, Conceptual approach, serta Comparative approach. Lihat Peter Mahmud Marzuki, 2005, Penelitian Hukum, Prenada Media, Jakarta, h. 96-155

6 Christophe Bellmann , Graham Dutfield \& Melendez-Ortiz, 2003, Trading in Knowledge : Development Perspectives on TRIPS, Trade and Sustainability, International Centre for Trade and Sustainable Development (ICTSD), Earthscan, London, h. 10
}

Generaal Agreement on Tariffs and Trade (GATT), which is administrated by the Geneva-based World Trade Organization (WTO). TRIPS establishes enforceable global minimum (and high) standars of protection and enforcement for virtually all of the most important IPRs in single agreement". TRIPs dengan standar minimumnya namun (high) wajib menjadi acuan dalam pengaturan HKI di seluruh negara anggota termasuk Indonesia. ${ }^{7}$

Berkaitan dengan pengaturan HKI sedunia setidaknya ada dua organisasi yang sangat berpengaruh yaitu WIPO dan WTO. Indonesia sebagai anggota WIPO memiliki hak dan kewajiban yang berbeda dengan sebagai negara anggota WTO. ${ }^{8}$ Sebagai negara anggota WTO pada akhirnya juga mewajibkan negara anggotanya tunduk pada Annex dari WTO, yaitu salah satunya adalah TRIPs Agreement. Kewajiban seluruh negara anggota untuk mengharmonisasikan sistem hukum HKI-nya ke arah Persetujuan TRIPs akhirnya juga mewajibkan mereka tunduk pada Konvensi Paris maupun Konvensi Berne, serta Konvensi Roma,

7 Eddy Damian, 2002, Hak Kekayaan Intelektual suatu Pengantar, Asian Law Goup Pty Ltd, Alumni, Bandung, h.36.

8 Tim Lindsey dkk.,2011,Hak Kekayaan Intelektual Suatu Pengantar, Alumni,Bandung, Cetakan ke -6, h.29 
karena TRIPs Agreement itu sendiri mengadopsi subtansi dari konvensikonvensi HKI tersebut di atas. Prinsip atau standar yang diatur TRIPs bagi perlindungan HKI mengacu pada prinsip utama WTO. Sistem hukum HKI secara dramatik mengalami perubahan berbasis WTO - TRIPS Agreement terhadap negaranegara anggota. ${ }^{9}$ Prinsip - prinsip yang melandasi pengaturan hubungan perdagangan bagi seluruh negara anggota WTO dikenal sebagai prinsip Most Favoured Nations Treatment (MFN), yaitu prinsip yang menekankan perlakuan yang sama bagi seluruh negara anggota WTO, serta prinsip National Treatment (NT) yaitu prinsip perlakuan nasional yang tidak boleh berbeda dengan negara anggota lainnya. ${ }^{10}$

Prinsip MFN dalam kerangka perlindungan HKI terkonstruksi berdasarkan Article 4 TRIPs, pada intinya

\section{Annette Kur and Marianne} Levin,2011,Intellectual Property Rights In a Fair World Trade Syatem-Proposal for Reforms of TRIPs, Edward Elgar Publishing Inc.,UK, h. 12. Selanjutnya dikemukakan '... the TRIPS as " to date .... The most comperehensive multilateral agreement on intellectual property rights. Indeed, TRPS has taken away a great deal of internal regulatory discretion.'

${ }^{10}$ Munir Fuady, 2008,"Pengantar Hukum Bisnis ; Menata Bisnis Modern di Era Global,"Citra Aditya Bakti, Bandung, h. 309, lihat juga Tomi Suryo Utomo,2009, "Hak Kekayaan Intelektual (HKI ) di Era Global sebuah Kajian Kontemporer," Graha Ilmu, Yogyakarta, h. 29 ketentuan ini mengatur bahwa keberpihakan, keuntungan, maupun perlakuan istimewa yang diberikan kepada suatu negara peserta TRIPs haruslah diberikan immediately dan unconditionally kepada warga negara lainnya yang juga merupakan peserta TRIPs seperti diatur dalam Article 4 TRIPS.

Secara lebih tegas Article 4.1 TRIPS mensyaratkan semua persetujuan yang dibuat dan ditandatangani dalam rangka HKI harus diperlakukan secara sama, serta tidak boleh ada penerapan ketentuan yang berbeda dan diistimewakan kepada suatu negara anggota tertentu. Dalam konteks ini, tidak boleh ada diskriminasi (Prinsip Non Discrimination). Contoh, Indonesia dalam menerima pendaftaran merek dari suatu negara anggota tertentu harus memberlakukan persyaratan yang sama pula bagi pendaftaran mereka dari negara anggota WTO lainnya. Keberpihakan dan perlakuan yang menguntungkan kepada warga salah satu negara anggota wajib diberlakukan kepada semua warga negara anggota WTO lainnya.

Prinsip MFN sebagaimana diatur dalam Article 4 TRIPs Agreement sesungguhnya juga dapat dikecualikan, dengan kata lain keperpihakan serta 
perlakuan istimewa kepada suatu negara anggota tertentu tidak dianggap pelanggaran jika perlakuan istimewa tersebut diberikan berkaitan dengan : perjanjian internasional dan bantuan hukum yang tidak semata-mata untuk perlindungan $\mathrm{HKI}$, perlakuan istimewa bukan dalam konteks $N T$ tetapi dalam kerangka Berne Convention dan Rome Convention, perlakuan istimewa tersebut diberikan sebelum berlakunya WTO dan sepanjang diberitahukan kepada Dewan TRIPS serta tidak menimbulkan diskriminasi yang tidak wajar bagi negara anggota WTO-TRIPs Agreement lainnya. ${ }^{11}$

Non Discrimination Principle yang kedua dalam TRIPs adalah National Treatment (NT) tercantum dalam Article 3.1 TRIPs Agreement. Pada initinya prinsip ini mempersyaratkan bahwa negara anggota tidak boleh memberikan perlakuan yang mengistimewakan serta menguntungkan warga negaranya terkait perlindungan terhadap produk-produk HKI, jika memberikan perlakuan istimewa kepada warga negara sendiri, maka wajib juga memberikan perlakuan istimewa yang sama kepada warga negara anggota WTO

11 Rahmi Jened,2003, Perlindungan Hak Cipta Pasca Persetujuan TRIPs, Yuridika Press, Fakultas Hukum Universitas Airlangga, Surabaya, h. 61 . lainnya. Meskipun sepintas tampak ada kesamaan antara prinsip NT dan prinsip Resiprositas, kedua prinsip tersebut sesungguhnya tidak sama, prinsip Resiprositas sering dikenal sebagai prinsip timbale balik, sementara itu tujuan Prinsip NT adalah untuk mencegah diskriminasi pada pasar domestik, menciptakan harmonisasi perdagangan internasional, meningkatkan efisiensi dalam perdagangan internasional, menstabilkan sistem pasar bebas, serta dapat mengurangi biaya -biaya dalam rangka pasar bebas serta memungkinkan negara kecil untuk turut mendapatkan manfaat (benefit) dari keberadaan negaranegara maju yang sering dalam kerjasamanya memberikan bantuan berupa grand.

Sebagaimana dikenal pengecualian dalam Prinsip $M F N$, pada Prinsip $N T$ juga dikenal pengecualian. Prinsip ini dapat dikecualikan bagi negara yang menggunakan special reservation sebagaimana diatur dalam Berne Convention dan Rome Convention, dengan persyaratan menyampaikan pemberitahuan kepada Dewan TRIPs berdasarkan Article 3 paragrah 1 TRIPs.

TRIPS Agreement selain mempersyaratkan diberlakukannya Prinsip MFN dan NT, jika dicermati juga 
penegasannya dalam perlindungan HKI secara internasional terletak pada pemenuhan standar minimum TRIPS dalam perundang-undangan nasional negara anggota. Dalam pengaturan HKI di negara anggota dipersyaratkan minimal harus sama dengan TRIPs, negara anggota diijinkan memperluas pengaturannya namun tidak boleh kurang dari standar TRIPs. Dalam kerangka pengaturan yang lebih luas dimaksudkan untuk memberikan perlindungan yang lebih baik kepada jenis jenis HKI yang sangat beragam yang dimiliki oleh suatu negara anggota.

Dalam rangka mengharmonisasikan ketentuan hukum HKI, bagi anggota negara berkembang diberikan kesempatan waktu 4 tahun dihitung sejak berlakunya WTO, serta 11 tahun bagi negara tertinggal

(Transitional

Arrangements) sebagaimana diatur dalam

Part VI TRIPs. Sehubungan dengan keberadaan Prinsip MFN, NT serta standar minimum dalam TRIPS Agreement, Peter S. Watson, mengemukakan pendapatnya sebagai berikut $:^{12}$
“...The Agreement on Made Related Aspects of Intellectual Property Rights on other hand, does appear to represent genuine movement toward the type of progress necessary for advancement on market access and competition policy concerns. TRIPs incorporates many of the provisions contained in the existing international agreements that protect intellectual property In this sense, TRIPs represents a major development of substantive law in the GATT/WTO system. While it does adopt the traditional GATT concepts of most favored nation status, national treatment and transparency TRIPs proscribes minimum standards of intellectual property protection that must be maintained by WTO members and requires Member States to take positive action to ensure protection of property rights. Finally TRIPs unlock the WTO's powerful dispute settlement system to IPR conflicts. Compared to GATT therefirm TRIPs represents a much more transparent and progressive approach to trade."

Kewajiban pelaksanaan Prinsip $M F N, N T$ serta standar minimum dalam rangka perlindungan HKI, sesungguhnya menyiratkan bahwa pengaturan TRIPs ini memberikan standar yang lebih tinggi dibandingkan dengan perjanjian-perjanjian internasional HKI lainnya terutama dalam rangka penegakan hukumnya. Namun demikian, TRIPs sesungguhnya

12 Peter S. Watson, 2000, Completing the World Trading System, Proposal for a Millenium Round,Kluwer Law International,Cambridge, $\mathrm{p}$. 31-32 
juga memberikan keleluasan untuk mengambil langkah-langkah, menggunakan hukum nasional negara anggota, asalkan harmoni dan tidak bertentangan dengan TRIPs, ketentuan tersebut dapat dicermati berdasarkan General Provisions and Basic Principles, khususnya Article 1.1. TRIPs dan Article 8 TRIPS $^{13}$.

Persetujuan TRIPs mempunyai pengaruh yang besar terhadap pembentukan pengaturan rezim HKI di negara-negara berkembang dan mempengaruhi munculnya sejumlah perjanjian dan produk hukum secara regional. $^{14}$ Berbagai jenis HKI yang wajib diproteksi dengan standar minimu TRIPs sebagaimana diatur dalam Part II TRIPS

13 General Provisions and Basic Principles, articel 1 (1): Member shall give effect to the provisions of this Agreement. Member may but shall not be obliged to, implement in their law more exstensive protection than is required by this Agreement provided that such protection does not contravene the provisions of this agreement. Members shall be free to determine the appropriate method of implimenting the provisions of this agreement whitin their own legal system and practice. Lihat Djamal, 2009, Hukum Acara Hak Kekayaan Intelektual di Indonesia, Penerbit Pustaka Reka Cipta, Bandung, h. 2.

14 Christophe Bellmann , Graham Dutfield \& Melendez-Ortiz, Op.Cit.,h. 13. Diantaranya:" ...the European Patent Convention, the EU Directive on the Legal Protection of Biotechnological Inventions, the Bangui Agreement Establishing an African Intellectual Property Organization (OAPI), the Harare Protocol on Patents and Industrial Design within the Framework of the African Regional Industrial Property Organization, and the Andean Community Common Regime on Industrial Property..."

Agreement meliputi : Copyright and related rights, Copyright and related rights, Geographical Indications, Industrial Design, Patents, Layout-designs (topographies) of integrated circuits, Protection of undisclosed information, Control of anti-competitive practices in contractual licenses. ${ }^{15}$

\subsection{Keberadaan Serta Harmonisasi Prinsip NT dan MFN Dalam} Pengaturan HKI Di Indonesia

Indonesia telah mengharmonisasikan serta membentuk undang-undang baru berkaitan dengan perlindungan Hak Kekayaan Intelektual sebagai wujud nyata pentaatan kewajibannya terhadap persetujuan TRIPs. Adapun perundangundangan tersebut meliputi: :UU No. 29 Tahun 2000 tentang Perlindungan Varietas Tanaman, UU No. 30 Tahun 2000 tentang Rahasia Dagang, UU No. 31 Tahun 2000 tentang Desain Industri, UU No. 32 Tahun 2000 tetang Desain Tata Letak Sirkuit Terpadu, UU No. 14 Tahun 2001 tentang Paten, UU No. 15 tahun 2001 tentang Merek, serta UU No. 19 tahun 2002 tentang Hak Cipta.

15 F. Scott Kief \& Ralph Nack, 2006, Internasional,United States and EuropeanIntellectual Property-Selected Source Material 2007-2008, Aspen Publishers,New York,h.51 
Pada intinya berbagai jenis HKI seperti tersebut di atas dapat dikelompokkan menjadi dua yaitu : Copyrights dan Industrial Rights.. Kedua penggolongan tersebut mendapat perlindungan hukum yang berlainan. Perlindungan hukum atas Hak Cipta (Copyrights) diberikan secara langsung tanpa harus memenuhi syarat apapun (Automatic Protection atau automatically protection system). Menurut Berne Convention perlindungan Copy Right tidak wajib untuk didaftar, sudah secara otomatis mendapat perlindungan begitu karya diwujudkan dalam karya nyata / expression work. Dalam hak cipta tidak diwajibkan untuk didaftar, akan tetapi Undang-Undang menganjurkan pendaftaran, karena pendaftaran perlu dilakukan untuk memudahkan pembuktian/kepastian hukum. Sertifikat pendaftaran bukan menjadi bukti kepemilikan yang sah tentang adanya HKI jika dapat dibuktikan sebaliknya.

Dalam Konvensi Berne, mewajibkan negara-negara peserta untuk menerapkan tiga prinsip dasar, yaitu : Prinsip National Treatment, Prinsip Automatic Protection, serta Prinsip Independence of Protection. ${ }^{16}$ Hak Cipta
(Copyright) sistem perlindungannya menganut Prinsip Automatic Protection, yaitu perlindungan hukumnya diberikan secara otomatis begitu karya cipta tersebut terwujud, jadi pendaftaran bukan merupakan suatu kewajiban. Sedangkan Hak atas Kekayaan Industrial (Industrial Property Rights) perlindungan hukumnya disebut dengan "fisrt to file system" atau Sistem Konstitutif, artinya pendaftar yang lebih dahulu diberikan perlindungan hukum atau sistem pendaftaran ini didasarkan pada pendaftaran pertama. Dalam konteks ini, pendaftaran merupakan suatu kewajiban untuk mendapatkan perlindungan hukum.

Sistem perlindungan hukum dalam bidang HKI baik yang bersifat otomatis maupun sistem pendaftaran pertama yang sekarang dianut di Indonesia sesungguhnya juga dianut di negaranegara anggota lainnya. Pengadopsian sistem perlindungan HKI sebagaimana diatur dalam TRIPs Agreement, termasuk di dalamnya harmonisasi terhadap prinsip $N T$ dan $M F N$ ke dalam politik hukum ${ }^{17}$

${ }^{16}$ Eddy Damian, 2005, Hukum Hak Cipta, Alumni, Bandung, h.15

17 Padmo Wahjono mendifinisikan Politik hukum sebagai kebijakan penyelenggara negara yang bersifat mendasardalam menentukan araharah, bentuk maupun isi dari hukum yang akan dibentukdan tentang apa yang dijadikan kriteria untuk menghukumkan sesuatu. Lihat Imam 
pengaturan HKI di Indonesia tentu membawa konsekuensi-konsekuensi yang wajib ditaati oleh negara Indonesia, termasuk pentaatannya terhadap prinsip NT dan MFN dalam konstruksi hukum HKI di Indonesia. Prinsip National Treatment dalam HKI mensyaratkan bahwa pemilik hak atas kekayaan intelektual asing harus diberi perlindungan yang sama dengan warga negara nasional. Article 3 TRIPs Agreement mengatur tentang Prinsip National Treatment. Dalam penerapannya di Indonesia misalnya dalam bidang Merek Terkenal berdasarkan prinsip NT ini berarti Indonesia wajib memberikan perlindungan terhadap pemilik merek terkenal asing sama dengan memberikan perlindungan pemilik merek terkenal dari warga negara Indonesia sendiri. Seamentara itu, Prinsip Most Favoured Nation (MFN) sebagai pengejawantahan Non Discrimination system mewajibkan bahwa perlindungan kepada pemilik HKI asing dari suatu negara wajib diberikan sama kepada pemilik HKI dari negara anggota yang lain (warga negara pemilik HKI dari negara anggota lainnya) atau dengan kata lain tidak boleh ada perlakuan kepada pihak asing yang berasal dari suatu negara lebih

baik dari pada perlakuan terhadap pihak asing dari negara lain. TRIPs Agreements mengatur Prinsip $M F N$ ini berdasarkan Article 4.

Implikasi dari keikutsertaan Indonesia sebagai negara anggota WTOTRIPs Agreement tidak dapat dipungkiri membawa konsekuensi Indonesia wajib mentaati kewajiban-kewajiban TRIPs termasuk didalamnya mengkonstruksi serta mengharmonisasikan hukum HKI sesuai dengan prinsip $N T$ dan $M F N$ dan kemudian mengimplementasikannya serta melakukan penegakan hukum di bidang itu.

Dalam U.U. Hak Cipta Indonesia, politik hukum berkaitan dengan keberadaan prinsip $N T$ dan $M F N$ tampak terkonstruksi pada Bagian Menimbang huruf $b$. dan Bagian Mengingat angka 2, serta Penjelasan Umum paragraph 2 dan Pasal 76 huruf c. U.U. No. 19 Tahun 2002. Secara eksplisit dikemukakan bahwa Indonesia menjadi anggota berbagai konvensi atau perjanjian internasional di bidang hak kekayaan intelektual pada umumnya dan Hak Cipta pada khususnya serta pengesahan Agreement Establishing the World Trade Organization berdasarkan U.U. No. 7 Tahun 1994. Lebih lanjut Pasal 76 U.U. No. 19 Tahun 2002 tentang 
Hak Cipta mengatur bahwa Undang-

ciptaan baik yang berasal dari warga Undang berlaku terhadap:

a. Semua ciptaan warga negara, penduduk, dan badan hukum Indonesia

b. Semua ciptaan bukan warga negara Indonesia, bukan penduduk Indonesia dan bukan badan hukum Indonesia yang diumumkan untuk pertama kali di Indonesia

c. Semua ciptaan bukan warga negara Indonesia, bukan penduduk Indonesia, dan bukan badan hukum Indonesia, dengan ketentuan :

(i) Negaranya mempunyai perjanjian bilateral mengenai perlindungan Hak Cipta dengan Negara Republik Indonesia atau

(ii) Negaranya dan Negara Republik Indonesia merupakan pihak atau peserta dalam perjanjian multilateral yang sama mengenai perlindungan Hak Cipta.

Berdasarkan ketentuan Pasal 76 U.U. No. 19 Tahun 2002 sebagaimana tersebut di atas, tampaknya jelas bahwa Prinsip NT telah mewarnai politik hukum yang mendasari lahirnya ketentuan hukum Hak Cipta baru pasca TRIPs Agreement di Indonesia, yaitu terkonstruksi menjadi U.U. No. 19 Tahun 2002 tentang Hak Cipta, yaitu yang pada prinsipnya memberikan perlindungan yang sama bagi negara Indonesia maupun dari warga negara lain sepanjang mereka adalah anggota dari WTO. Keberadaan dan implikasinya dari Prinsip NT, terlihat nyata dalam bentuk tatanan norma dalam hukum Hak Cipta, meskipunt keberadaan prinsip NT dan MFN tidak setegas dalam U.U. Penenaman Modal yang secara eksplisit penormaannya sangat jelas itu adalah pengadopsian prinsip $N T$ dan $M F N$.

Seperti halnya dalam hukum Hak Cipta, keberadaan Prinsip NT dan $M F N$ dalam politik hukum Merek di Indonesia tidak secara eksplisit disebutkan, namun itu bukan berarti dalam Undang-Undang Merek di Indonesia ${ }^{18}$ tidak mengadopsi Prinsip non discrimination system tersebut. Pengejawantahan Prinsip NT tampak dalam ketentuan Pasal 3 Bab II bagian kedua, Bab III bagian kedua, Pasal 18Pasal 20, Pasal 21-38, Bab V , Bab VIII, Bab IX sampai dengan Bab XVI. ${ }^{19}$ Berkaitan dengan keberadaan ketentuan tersebut, maka dalam kasus pembatalan Merek Buddha Bar, yaitu suatu merek yang berasal dari Badan Hukum Perancis

19 Pembatalan Merek Buddha Bar Di Indonesia Dikaitkan Dengan Prinsip National Treatment Dalam TRIPs Serta Akibat yang Dapat Ditimbulkannya Bagi Indonesia, Jurnal FH Universitas Padjadjaran, http://fh.unpad.ac.id/repo/?p=3985, diakses tanggal 10 Nopember 2013. 
dianggap telah terjadi pelanggaran atas Prinsip NT dan melanggar ketentuan Pasal 5 hurua U.U. No. 15 Tahun 2001 karena pihak Buddha Bar menggunakan kata "Buddha" dalam mereknya dan dituntut agar pendaftaran mereknya di Dirjen HKI dibatalkan, namun di sisi lain pihak pemilik merek Indonesia yang juga menggunakan kata "Budda" tidak dituntut untuk membatalkan mereknya. Fenomena tersebut dirasakan sebagai diskriminasi perlakuan antara pemilik merek nasional dengan pemilik merek asing sehingga dianggap melanggar Prinsip Non Discrimination.

Setiap negara anggota dalam perjanjian WTO-TRIPs Agreement memang dipersyaratkan untuk mentaati standar minimum dalam perjanjian tersebut, termasuk didalamnya setandar ini dikaitkan dengan kewajiban mentaati prinsip MFN dan NT. Indonesia sebagai salah satu negara anggota yang sudah mengharmonisasikan pengaturan HKI-nya ke arah TRIPs sudah sepantasnya mentaati standar minimum tersebut dengan tetap memiliki keleluasan dalam koridor Article 1.1. TRIPs yaitu tentang Nature and Scope of Obligations, serta Article 8.1. TRIPs, yaitu yang pada intinya membolehkan suatu negara anggota dalam amandemen ketentuan hukum HKI mengadopsi langkah-langkah yang dianggap penting dalam rangka melindungi kesehatan masyarakat, nutrisi, kepentingan umum yang berkaitan dengan sektor penting dalam bidang sosial dan ekonomi, serta perkembangan teknologi, sepanjang upaya dan langkah-langkah tersebut konsisten dengan pengaturan dalam TRIPS Agreement. Dalam konteks usulan pembatalan merek asing "Buddha Bar", tampaknya karena berkaitan dengan sektor penting bidang sosial yaitu bertentangan dengan kepatutan dan kepentingan dari suatu negara (seperti dalam kasus ini berkaitan dengan agama), maka menjadi relevan jika pembatalan merek yang menggunakan atribut agama dimohonkan pembatalannya. Namun demikian, sudah sepantasnya jika warga negara sendiri yang juga menggunakan kata-kata atau atribut keagamaan seperti itu sebagai merek, juga dimohonkan pembatalan. Hal tersebut, selain karena pentaatan terhadap prinsip non discrimination system, juga sebagai penghormatan (respecting) terhadap halhal yang berkaitan dengan keagamaan yang sesungguhnya lebih berkaitan dengan nurani dan keyakinan, yang seharusnya tidak memasuki ranah komersial.

Keberadaan prinsip $M F N$ dan $N T$ dalam TRIPs Agreement yang 
sesunguhnya mendukung substansi norma hukum HKI yang bersifat universal yang juga sering diindikasikan sebagai free trade principles, dalam pengimplementasiannya di negara-negara anggota tidak mudah, meskipun diberikan keleluasan sebagaimana diatur dalam Article 1 TRIPs, namun dengan bercermin dari kasus IndiaPatent Protection for Pharmaeutical and Agricultural Chemical Product 1997, kesempatan untuk tunduk pada ketentuan Article 1 TRIPs ternyata dipersempit dan dibatasi. $^{20}$ Prinsip $M F N$ yang meskipun mengedepankan non discrimination system, ternyata tidak mudah diaplikasikan pada negara-negara anggota yang berbeda atau unequel size seperti dari negara maju dan negara berkembang, termasuk di dalamnya Indonesia. Dalam perspektif ekonomi sekalipun, penerapan prinsip MFN ini dikemukakan lebih menguntungkan pihak yang kaya dan merugikan pihak yang miskin, $M F N$ adoption by a country benefits its richer trading parther whereas it hurts the poorer one. ${ }^{21}$

20 Gail E. Evans, 2005, TRIPS and The Sufficiency of the Free Trade Principles, the Journal of World Intellectual Property, Vol. 2 Issue 5, Online ISSN 1747-1796, p,724.

21 Kamal Saggi, 2009, The MFN Clause Welfare and Multilateral Cooperation Between Countries of Unequal Size, Journal of Development
Dalam Undang-Undang Paten di Indonesia yaitu U.U. No. 14 Tahun 2001 dalam Penjelasan Umum-nya menegaskan tentang Prinsip standar minimum dalam TRIPs , yaitu secara eksplisit dinyatakan bahwa "Persetujuan TRIPs hanya meletakkan persyaratan minimum pengaturan mengenai kegiatan-kegiatan yang boleh atau tidak boleh dipatenkan. Berkaitan dengan minimum requirements juga terlihat terkonstruksi dalam Pasal 30 Ayat (1) U.U. Paten. Dalam Penjelasan Pasal tersebut disebutkan secara eksplisit bahwa "ketentuan ini merupakan syaratsyarat yang disebut sebagai persyaratan minimum (minimum requirements), yang dimaksudkan untuk memudahkan pemohon dalam memperoleh tanggal penerimaan yang menggunakan first to file , serta untuk memberikan pelayanan dan menyesuaikan dengan syarat minimum tanggal penerimaan bagi permohonan paten yang pendaftarannya berdasarkan Patent Cooperation Treaty. ${ }^{22}$

\section{SIMPULAN DAN SARAN}

\section{Simpulan}

Economics 88, J.Jdeveco, ISSN 0304-3878, p. 133.

${ }^{22}$ Lihat Penjelasan U.U. No. 14 Tahun 2001 Tentang Paten Pasal 30 Ayat (1). 
Berdasarkan pembahasan pada bab sebelumnya maka dapat ditarik simpulan sebagai berikut :

1) Pengaturan Prinsip Non Discrimination System, yaitu Prinsip National Treatment (NT) diatur secara tegas berdasarkan Article 3 TRIPs Agreement yang substansinya pada intinya melarang adanya perlakuan istimewa pada warga negara sendiri berkaitan dengan perlindungan Hak Kekayaan Intelektual dan memberikan perlakuan yang berbeda (mendiskriminasikan) warga negara asing dari negara anggota. Sementara itu Prinsip Most Favoured Nations MFN) diatur berdasarkan Article 4 TRIPs Agreement, yang substansinya menekankan bahwa perlakuan istimewa kepada pemilik Hak Kekayaan Intelektual suatu negara anggota tertentu, wajib juga diberikan perlakuan yang sama secepatnya dan tanpa syarat kepada pemilik Hak kekayaan Intelektual negara anggota lainnya dari WTO-TRIPs Agreement.

2) Implikasi keikutsertaan Indonesia sebagai anggota WTO-TRIPS Agreement berkaitan dengan keberadaan Prinsip $M F N$ dan $N T$ adalah mengaplikasikan Prinsip NT dan $M F N$ tersebut ke dalam perundang-undangan Hak Kekayaan Intelektual di Indonesia seperti halnya dalam U.U. No. 19 Tahun 2002 Tentang Hak Cipta, U.U. No. 15 Tahun 2001 Tentang Merek, serta U.U. No. 14 Tahun 2001 tentang Paten. Meskipun keberadaan Prinsip $M F N$ dan NT serta standar minimum TRIPS sudah tertuang secara implisit maupun eksplisit dalam perundang-undangan Hak Kekayaan Intelektual di Indonesia, namun seperti halnya negara berkembang lainnya tidak mudah mengaplikasikannya karena prinsip yang berbasis universal ini tidak selalu harmoni dengan kondisi sosial dan ekonomi suatu negara yang berada dalam posisi unequal size, termasuk di dalamnya Indonesia.

\section{Saran}

Diharapkan keberadaan Prinsip NT dan $M F N$ agar diatur secara eksplisit dalam perundang-undangan Hak Kekayaan Intelektual di Indonesia untuk memudahkan pentaatan secara konsisten pada kewajiban TRIPs, serta untuk menegaskan sikap ketika mengatur hal yang spesifik bagi kepentingan ekonomi dan sosial suatu negara sebagaimana dimungkinkan berdasarkan Article 1 TRIPs Agreement. 


\section{DAFTAR PUSTAKA}

\section{BUKU}

Annette Kur and Marianne Levin, 2011, Intellectual Property Rights In a Fair World Trade SyatemProposal for Reforms of TRIPs, Edward Elgar Publishing Inc.,UK.

Direktorat Jendral Hak Kekayaan Intelektual Departemen Hukum dan Hak Asasi Manusia Republik Indonesia, 2007, Penegakan Hukum di Bidang Hak Kekayaan Intelektual

Eddy Damian, 2002, Hak Kekayaan Intelektual Suatu Pengantar, Asian Law Goup Pty Ltd, Alumni, Bandung

F. Scott Kief \& Ralph Nack, 2008, Internasional,United States and European-Intellectual PropertySelected Source Material 2007-2008, Aspen Publishers, New York

Imam Syaukani \& A. Ahsin Thohari, 2006, Dasar-Dasar Politik Hukum, PT Raja Grafindo Persada, Jakarta

Jhony Ibrahim, 2006, Teori dan Metode Penelitian Hukum Normatif, Bayu Publishing, Malang

Munir Fuady, 2008,"Pengantar Hukum Bisnis ; Menata Bisnis Modern di Era Global,"Citra Aditya Bakti, Bandung

Peter S. Watson, 2000, Completing the World Trading System, Proposal for a Millenium Round, Kluwer Law International, Cambridge

Peter Mahmud Marzuki, 2005, Penelitian Hukum, Prenada Media, Jakarta
Rahmi Jened,2003, Perlindungan Hak Cipta Pasca Persetujuan TRIPs, Yuridika Press, Fakultas Hukum Universitas Airlangga, Surabaya.

Tim Lindsey dkk.,2011,Hak Kekayaan Intelektual Suatu Pengantar, Alumni,Bandung

Tomi Suryo Utomo,2009, "Hak Kekayaan Intelektual (HKI ) di Era Global sebuah Kajian Kontemporer," Graha Ilmu, Yogyakarta

\section{JURNAL}

Christophe Bellmann, Graham Dutfield \& Melendez-Ortiz, 2003, Trading in Knowledge : Development Perspectives on TRIPS, Trade and Sustainability, International Centre for Trade and Sustainable Development (ICTSD), Earthscan, London,

Gail E. Evans, 2005, TRIPS and The Sufficiency of the Free Trade Principles, the Journal of World Intellectual Property, Vol. 2 Issue 5, Online ISSN 1747-1796

Kamal Saggi, 2009, The MFN Clause Welfare and Multilateral Cooperation Between Countries of Unequal Size, Journal of Development Economics 88, J.Jdeveco, ISSN 0304-3878

Mooneeram \& Chadee Varsha, 2013, Understanding the Legal Framework of the Most Favoured Nation Rule from a SIDS perspective, ICITI, ISSN:16941225, University of Mauritius, Reduit Mauritius 
PERATURAN PERUNDANG-

\section{UNDANGAN}

UU No. 14 Tahun 2001 tentang Paten.

UU No. 15 tahun 2001 tentang Merek.

UU No. 19 tahun 2002 tentang Hak Cipta

The WTO TRIPs Agreement

\section{INTERNET}

Pembatalan Merek Buddha Bar Di Indonesia Dikaitkan Dengan Prinsip National Treatment Dalam TRIPS Serta Akibat yang Dapat Ditimbulkannya Bagi Indonesia, Jurnal FH Universitas Padjadjaran, http://fh.unpad.ac.id/repo/?p=3985 